Cahiers de civilisation médiévale

\title{
Sophie BROUQUET, La vie des femmes au Moyen Âge
}

\section{Julie Pilorget}

\section{(2) OpenEdition \\ Journals}

Édition électronique

URL : https://journals.openedition.org/ccm/8195

DOl : $10.4000 / \mathrm{ccm} .8195$

ISSN : 2119-1026

\section{Éditeur}

Centre d'études supérieures de civilisation médiévale/Université de Poitiers

\section{Édition imprimée}

Date de publication : 1 septembre 2021

Pagination : 294-296

ISBN : 978-2-490783-10-6

ISSN : 0007-9731

\section{Référence électronique}

Julie Pilorget, "Sophie вrouauet, La vie des femmes au Moyen Âge », Cahiers de civilisation médiévale [En ligne], 255 | 2021, mis en ligne le 01 septembre 2021, consulté le 06 février 2022. URL : http:// journals.openedition.org/ccm/8195; DOI : https://doi.org/10.4000/ccm.8195

\section{(c) (i) $\odot$}

La revue Cahiers de civilisation médiévale est mise à disposition selon les termes de la Licence Creative Commons Attribution - Pas d'Utilisation Commerciale - Pas de Modification 4.0 International. 
Sophie Brouquet, La vie des femmes au Moyen Âge, Rennes, Éditions Ouest-France, 2019.

Cette quatrième édition de La vie des femmes au Moyen Âge par Sophie Brouquet aux Éditions OuestFrance témoigne de l'attention croissante portée à ce sujet au cours des dernières années. Si l'intérêt des chercheurs pour la place des femmes au sein de la société médiévale est ancien, on constate toutefois une multiplication des travaux en la matière depuis les années 2000 et surtout une popularité grandissante du sujet auprès du grand public. On ne compte plus désormais le nombre de romans ou séries consacrés à la question, dans lesquels cependant de nombreux fantasmes historiographiques ont encore cours. Aussi, on ne peut que saluer la réédition de cet ouvrage qui, " loin de toute idéalisation [...] ou de tout pathos " (p. 5), révèle toute la diversité de la condition des femmes au Moyen Âge.

Professeure d'histoire médiévale à l'université de Toulouse II-le Mirail, S. Brouquet produit ici un 
ouvrage de vulgarisation scientifique d'une grande rigueur, richement sourcé et documenté, notamment du point de vue iconographique. À ce titre, on peut imaginer qu'outre le grand public, les professeurs du secondaire trouveront dans ce livre de nombreuses ressources pour intégrer les femmes à leurs leçons, à l'heure de la réforme des programmes scolaires qui relègue au second plan l'histoire des femmes et du genre.

Organisé autour de cinq thématiques, l'ouvrage s'ouvre sur une première partie consacrée aux différents âges de la vie. Ce chapitre propose une perception dynamique des phénomènes venant ponctuer la vie des femmes, de la petite enfance à la vieillesse. On relèvera notamment des développements très intéressants consacrés la naissance et aux premières années de la vie d'une petite fille, ainsi qu'à l'éducation des jeunes filles. Plusieurs pages sont ainsi consacrées au traité adressé par le chevalier de La Tour-Landry à ses filles. Le mariage chrétien constituant la clef de voûte de la société médiévale, l'a. revient également en détail sur l'élaboration de ce sacrement au fil des siècles et à la condition de la femme mariée soumise à l'autorité de son époux. On regrettera, cependant, la faible place occupée par la veuve et la femme âgée, trop rapidement évoquées en conclusion du chapitre. Le veuvage apparaît pourtant, pour quantité de femmes, comme une seconde vie pendant laquelle s'ouvre à elles l'opportunité d'accroître leurs biens, voire d'accéder à la prospérité. Il faut, en réalité, attendre le troisième chapitre consacré aux femmes en famille pour que l'a. revienne plus en détail sur leur sort, notamment au travers de la figure de la grand-mère. Ces deux chapitres auraient pu d'ailleurs, semble-t-il, ne former qu'un seul bloc, puisqu'il est beaucoup question dans ce dernier du rapport des femmes à la maternité, ainsi que de la figure de la marraine...

Le deuxième chapitre de l'ouvrage est consacré, quant à lui, au corps des femmes « désiré et redouté » (p. 19). Si le corps féminin doit être maîtrisé, il est aussi largement fantasmé. La poésie courtoise et le théâtre de la fin du Moyen Âge fournissent ainsi de nombreuses informations quant aux canons de la beauté féminine. La femme idéale est alors celle à la peau blanche, à la longue chevelure blonde, aux bras minces et aux hanches étroites que ses vêtements doivent mettre en valeur. L'ouvrage revient ainsi longtemps sur la mode aristocratique et les extravagances vestimentaires de l'époque. Ces développements sont également l'occasion pour l'a. d'évoquer l'intimité des couples mariés et la peur qu'incarne également le corps féminin chez les hommes d'Église.
Fille d'Ève, la femme reste l'« ennemie principale des clercs » (p. 54), celle en qui se cache le diable. C'est alors l'occasion pour S. Brouquet de rappeler que contrairement à une idée reçue qui a la vie dure, « la croyance aux sorcières n'est pas l'apanage du Moyen Âge » (p. 58). C'est en réalité à la Renaissance que la chasse aux sorcières connaît son apogée. Cette période marque en effet un certain renfermement pour les femmes qui disposaient auparavant de nombreuses possibilités d'exercer des rôles économiques, sociaux et religieux d'importances, comme le rappelle le quatrième chapitre de l'ouvrage.

Intitulé «femmes en société »(p. 79), ce troisième chapitre traite en premier lieu de la vie quotidienne des femmes à la campagne. Dans un monde qui reste essentiellement rural, les femmes ont un grand rôle dans les travaux des champs, même si elles ne jouent pas à parts égales avec les hommes. Elles se voient ainsi exclues des semailles, et ce pour des raisons tant physiques que symboliques : la terre étant femme, c'est à l'homme que revient la charge d'y faire pénétrer la semence. Cependant, elles contribuent aux fenaisons en juin, participent à la confection des gerbes de la moisson fin juillet et cueillent le raisin aux vendanges de septembre. Elles s'occupent également de la garde des troupeaux - on pense à Jeanne d'Arc dans les premières années de sa vie -, traient les vaches ou les chèvres, barattent le beurre, fabriquent le fromage, etc. Cette complémentarité des travaux masculins/féminins se retrouve en ville au sein des ateliers de marchands ou d'artisans. Les épouses de ceux-ci tiennent la boutique, et ont souvent reçu l'instruction nécessaire pour tenir la comptabilité - elles savent donc écrire et compter. Elles demeurent dans la dépendance du mari, mais dirigent par ailleurs les employés et les apprentis. Les femmes jouent également un rôle actif dans le petit commerce d'alimentation. Cela étant, comme le rappelle l'a., leurs salaires restent toujours inférieurs à ceux des hommes et de nombreuses suspicions pèsent à leur encontre (p. 88). Le Moyen Âge a donc offert aux femmes un large éventail d'activités, certaines échappent toutefois à cette condition laborieuse : les aristocrates et les religieuses. Leurs quotidiens respectifs ne riment cependant pas avec oisiveté. Les femmes de la noblesse se consacrent à la gestion et bonne marche de leur maison. S. Brouquet, également auteure d'un ouvrage consacré aux chevaleresses (Sophie Brouquet, Chevaleresses : une chevalerie au féminin, Paris, Perrin [Pour l'Histoire], 2013) a cœur de rappeler que de nombreuses aristocrates prirent part à la vie publique et politique de leur temps, comme Marie de Champagne. Fille d'Aliénor d'Aquitaine et 
du roi de France Louis VII, elle endossa à plusieurs reprises le rôle de lieutenante puis de régente du comté de Champagne (p. 94). Par ailleurs, si au haut Moyen Âge, les fondations religieuses féminines sont rares, on assiste à une multiplication des institutions et des formes de clôture pour les femmes à partir des $\mathrm{XII}^{\mathrm{e}}$-XIII ${ }^{\mathrm{e}}$ s., notamment sous l'impulsion des ordres mendiants. Ainsi, en 1212, sainte Claire d'Assise crée l'ordre des sœurs mineures qui lui doivent leur nom de Clarisses (p. 102). D'autres femmes enfin s'engagent au service des malades comme les sœurs hospitalières. Certaines abbesses bénéficièrent d'ailleurs d'une telle aura, qu'elles devinrent des modèles pour de nombreuses femmes, ainsi Hildegarde de Bingen (1098-1179) ou Colette de Corbie (1381-1447).

C'est d'ailleurs sur cette question bien connue des « modèles » féminins (p. 107) que se conclut l'ouvrage dans un court chapitre consacré aux exemples à suivre que sont les hérö̈nes de l'Antiquité, les saintes martyrs et la figure de Marie, l'« idéal inaccessible» (p. 122). À l'issue de notre lecture, nous exprimons toutefois deux regrets : celui tout d'abord de la faible place accordée au haut Moyen Âge dans les développements et celui de la bibliographie qui aurait mérité une mise à jour depuis la première édition en 2009. Cela étant, on retiendra davantage ici les qualités de l'ouvrage qui, outre sa grande rigueur scientifique, témoigne d'un réel souci pédagogique et qui fourmille d'images donnant à voir la condition des femmes au Moyen Âge dans toute sa diversité.

Julie Pilorget

UMR 8596 - Centre Roland Mousnier Université Paris IV Sorbonne 